\title{
Observational Study on Standard Practices of Nurses in Birth Asphaxia Management at a Tertiary Care Hospital, Lahore, Pakistan
}

\author{
Sana Noor*, Kousar Praveen, Muhammad Hussain, Muhammad Afzal, Syed Amir Gilani \\ Lahore School of Nursing, The University of Lahore, Punjab, Pakistan.
}

\begin{abstract}
Background: Neonatal mortality is the death of newborn baby in first 28 days of life. Approximately 1 million newborn die in early 24 hours and 2 million more will be die in next 7 days of birth. Birth asphyxia is a medical condition which results due to lack of oxygen to newborn and last for long time, causing different morbidities and physical harm. It is the third major cause of newborn death, according to world health organization.
\end{abstract}

Aim: Aim of the study was to observe the practices of nurses for adherence on standard protocols towards birth asphyxia management.

Methods: A descriptive cross-sectional study was conducted at a tertiary care hospital. The population was n=153 nurses, working in labour room and nursery. Study duration was 4months. Data was collected by observational checklist consisted of 19 items to observe the practices of nurses. Data was analyzed by the categories of the $<60$ show poor practices, 61-74 gives average while $>75$ show good practices. Ethical approval was taken from participants as in written consent.

Results: Majority of Nurses $83 \%$ Nurses having experience above 10 years and show good practices towards management of birth asphyxia and $38 \%$ have good practices having age 25 years to 34 years. While the nurses having experience of less than five years $44 \%$ and age under 24 years $(11 \%)$ show poor practices.

Conclusion: Early detection of Birth asphyxia and management is critical to reduce neonatal mortality. Experienced nurses show good practices but there was some problems due to which standard protocols could not followed, as lack of staff nurses, bad attitude, lack of equipments and overburdened.

Keyword: Birth Asphyxia, Resuscitation, Neonates, Bag-mask Ventilation, Health care practitioner, Standard protocols.

\section{INTRODUCTION}

Neonatal mortality decline accounts for about half of under-5 deaths worldwide. It is estimated that $50 \%$ stillbirths occur during intrapartum, accounting for 1.3 million deaths per year. Birth asphyxia contribute to approximately one-quarter of neonatal deaths, most of them can be managed by resuscitation and provision of quality care [1].

Premature births in developing countries leads to 4 million deaths, approximately $23 \%$. It estimates that 120 million infants develop birth asphyxia in developing countries and undergo resuscitation, and 900,000 die each year. The risk of dying due to birth asphyxia changes in different countries. The specific cause of prenatal mortality rate related to birth asphyxia is between 10 and 20 per 1000 births [2].

Prevalence of birth asphyxia was found to be $39.7 \%$ in developing countries. Many risk factors was identified and modified [3].

Neonatal mortality is the death of newborn baby in first 28 days of life. Which is increasing day by day and undergone to decline [4].

*Address correspondence to this author at the Lahore School of Nursing, The University of Lahore, Punjab, Pakistan.

E-mail: sananoor1305@gmail.com
Approximately 1 million newborn die in early 24 hours and 2 million more will be die in next 7 days of birth [5]. According to a survey conducted in Pakistan, the incidence rate of perinatal asphyxia is approximately $3.3 \%$. While mortality rate reported in Lahore was nearly $50 \%$ in first week after birth due to asphyxia [6].

Birth asphyxia is the leading cause of neonatal mortality and contribute to $29 \%$ of the deaths in the country. Different causes of asphyxia are cord prolapse, prolong delivery, placenta abruption, hypoxemia and infection of mother and baby. In Kenya, prematurity is third major reason for the birth asphyxia due to gestational age less than 37 weeks [7].

Birth asphyxia is neurological defect with lower Apgar score of 1 and 5 minutes, arterial PH and lack of oxygen intake and failure to maintain spontaneous respiration at birth [8].

Birth asphyxia is a medical condition which results due to lack of oxygen to newborn and last for long time, causing different morbidities and physical harm. It is the third major cause of newborn death, according to world health organization [9].

Standard protocols have been developed over time to check the performance of neonate resuscitation with birth asphyxia. However, inadequate resuscitation practices are associated 
with increase in neonatal deaths with birth asphyxia in the first 24 hours. It is expected that about 1 in 10 babies need help or artificial breathe immediately after birth [10].

Umbilical cord $\mathrm{pH}$ is very important for the diagnosis of birth injuries as hypoxic ischemia HI, also called oxygen-depriving events. In the first 24 hours of life, newborn having $\mathrm{pH}$ between 7.0 and 7.11 causes $10-15 \%$ of severe neurological outcomes as hemorrhage, hypoxic-ischemic encephalopathy (HIE), cerebral palsy and birth asphyxia. Birth asphyxia lead to brain damage and seizures when umbilical cord arterial $\mathrm{pH}$ rises to 7.0. Acidosis occurs due to reduced delivery and transport of oxygen to the placenta from the maternal to fetal side. Many neonate with birth asphyxia and low Apgar scores, often have a normal $\mathrm{pH}$ of 7.28 [11].

Sarnat scoring is grading system for hypoxic-ischemic encephalopathy of the newborn (HIE), abnormality caused by insufficient oxygen supply at birth. Hypoxia is manifested as neuromuscular control, altered consciousness, complex reflexes, altered muscle tone, and seizures. Its severity is marked by the level of Apgar score. The scoring system is described as, a score of 0 is normal, a score of $1-10$ is mild, and $11-14$ is moderate while highest score is 22 also called severe status of hypoxic ischemia [12].

Implementation of resuscitation programs have declined intrapartum, stillbirth and early neonatal mortality. Challenges have faced with respect to provide skilled professionals, treatment, and quality of care. The combination of resuscitation steps and strategies with effective education has resulted in reduced rates of asphyxia-related newborn deaths [1].

\section{RESEARCH OBJECTIVE}

To assess the practices of nurses working in Nursery and labour room towards management of birth asphyxia in tertiary care hospital, Lahore, Pakistan.

\section{LITERATURE REVIEW}

Birth asphyxia is a term in which newborn undergone delayed respiration just after the delivery. Prevalence rate of birth asphyxia in neonates was about $21.1 \%$. According to Kawo Urassa, Killeo and Massawe (1995) it is very high as compared to previous reported cases $(10.4 \%)$ [13].

Resuscitation training program was started in 1987 in American Academy of Neonates. Since then, few studies have changed the resuscitation practices on newborn. There was marked reduction in neonatal mortality approximately as high as 30 to $40 \%$. Most important component of helping baby breathe is training of birth attendants to be provided which is the golden minute. Timely provision of management towards drying the baby, wrap and warm in dry cloth, stimulate to breathe and start bag and mask ventilation. Most of neonates can be saved immediately, who are not breathing at birth [14].
Health care practitioner (HCPs) were the most expert personnel who miss the most important protocol as to keep warm and dry immediately after birth. This neglected behaviors may cause death of newborn by hypothermia. This implies that with limited resources only simple interventions can improve breathing. As drying the baby, kept them warm and airway clearance by good nursing skills can avert the dying baby from asphyxia [15].

From several studies it has been noted that nurses and midwifes had a considerable gap in all areas of new born care and resuscitation practices. While, other studies had identified no competency gap toward neonatal resuscitation practices. A study in Kenya on skills of neonatal resuscitation had indicated that different neonatal resuscitation steps, as airway clearance was the most commonly performed step (85\%), drying and stimulation fairly performed $(60 \%)$ while bad and mask ventilation was the least $(45 \%)$ performed step of neonatal resuscitation [16].

Another cross-sectional study in Ethiopia showed that the mean knowledge scores of midwives and nurses were $42.8 \%$ and $43.9 \%$ respectively. In this study $64.2 \%$ of nurses respond to the correct suctioning, $66.7 \%$ Effective mask ventilation, $60.4 \%$ depth of chest compression during CPR. The finding of this study had implied that emphasis should be enhanced on the performance of nurses towards neonatal resuscitation [17].

\section{METHODOLOGY}

A cross sectional quantitative study design was done at tertiary care hospital in Lahore. This study took 4 months, from January 2020 to May 2020.The target population of study was nurses who were working in labour room and nursery. Slovin's sampling formula was used to find the sample size of the study population. Where, $\mathrm{n}=$ sample size, $\mathrm{N}=$ number of total population, $\mathrm{e}=$ margin of error was 0.05 when confidence interval is $95 \%$ [18]. Total population is 250 , so according to formula: $n=N / 1+(N)(E)$. So, sample size is 153. Convenient sampling technique was used to collect data. All nurses and midwives who are working in labour ward and nursery was included with Job experience from 1 year or more than 10 years. Graduate, Diploma, Degree and Specialized nurses. Trainee nursing and students were excluded having Job experience less than 1 year. Those nurses who will not working in nursery and labour room.

\section{Data Collection Method}

Observational checklist Adopted from [2] observational checklist was used for data collection to determine the practices of nurses for management of birth asphyxia. Data collection will be performed by direct observation by author at Labour room and Nursery. Data will be collected at Morning and Evening shift in a week (Monday to Sunday). Tool items consisted of 2 parts, 1) Demographic Data, 2) Observational Checklist=19. 


\section{Data Analysis}

Data is collected through checklist having 19 items of standard protocols by observing practices of 153 participants. Collected data is analyzed and computed using frequencies, table and percentage by SPSS version 25.0.

\section{Ethical Approval}

The study was conducted after institutional from Lahore School of Nursing, The University of Lahore and Organizational ethical committee from hospitals. Informed consent was taken from participants and their privacy was kept confidential.

\section{DATA ANALYSIS PROCEDURE}

Table 1. Socio-Demographic Variables.

\begin{tabular}{|l|c|c|}
\hline Demographic Characteristic & $\mathbf{N 1 5 3}$ & Percentage 100\% \\
\hline Gender & 25 & $16.3 \%$ \\
\hline Male & 128 & $83.7 \%$ \\
\hline Female & 100 & $65.4 \%$ \\
\hline Education & 53 & $34.6 \%$ \\
\hline Diploma of Midwifery & 18 & $11.8 \%$ \\
\hline BSN & 58 & $37.9 \%$ \\
\hline Age group & 59 & $38.6 \%$ \\
\hline $20-24$ year & 18 & $11.8 \%$ \\
\hline $25-29$ year & 12 & $7.8 \%$ \\
\hline $30-34$ year & 34 & $22.2 \%$ \\
\hline $35-39$ year & 68 & $44.4 \%$ \\
\hline Experience & 39 & $25.5 \%$ \\
\hline 2 years & 116 & $75.8 \%$ \\
\hline 5 years & 37 & $24.2 \%$ \\
\hline 10 years & \\
\hline Above 10 years & \\
\hline Designation & \\
\hline Charge nurse & \\
\hline Register nurse & \\
\hline
\end{tabular}

\section{Demographic Characteristics Of Participants (Table 1)}

The total response was 153 participants, 25(16.3\%) were male and majority participants were $128(83.7 \%)$ female. The age of the participants ranged from 20 to 39 . Majority participants with age group 25 to 34 was $38.6 \%, \mathrm{n}=59$ and age groups (20-24) \& (35-39) was $11.8 \%, \mathrm{n}=18$. Majority of nurses and midwifes belongs to ten years' experience $(44.4 \%), n=68$. Some of the participants have experience of five years as $(22.2 \%), n=34$. $(25.5 \%), n=39$ have above ten years Majority belongs to charge Nurses designation with BPS $=16$ with $(75.8 \%), n=116$. While $(24.2 \%), n=37$ were registered nurses. All the respondents had good experience in different levels of nursing and midwifery. Mostly Nurses had Diploma in Midwifery $(65.4 \%), \mathrm{n}=100$. While the Registered Nurses had $(\mathrm{BSN})$ Degrees $(34.6 \%), \mathrm{n}=53$.
On management of newborn resuscitation, Out of 153 , majority of participants $145(94.8 \%)$ Wipe the mouth of the newborn with clean gauze. While some of them 8(5.2\%) don't wipe the mouth with clean gauze. Majority of participants, 133(86.9\%) remove wet cloth and cover the baby with warm cloth, and remaining 22(13.1\%) do not wrap in dry cloth. Most of nurses $139(90.8 \%)$ quickly clear airway, the rest of $14(9.8 \%)$ do not clean the airway.

Majority of participants $138(90.2 \%)$ who responded that keep the baby on flat surface and neck is slightly extended one side to open the airway is a good practice, and a very little 15(9.8\%) do not practice it. Those respondents, 129(84.3\%) checked that, If the baby cannot breathe, apnea, gasping or heart rate is less than $100 \mathrm{~b} / \mathrm{min}$, start ventilating with bag and mask while some of them $24(15.7 \%)$ do not practice this protocol. Majority participants $124(81.0 \%)$ select suitable size of mask to cover the chin, mouth and nose and make sure that the mask is sealed over the nose and mouth. Most of them $114(75.5 \%)$ checked that Once the seal is checked and chest is moving, start ventilation and keep correct rate (40 breaths per minute). Some of them 39(25.5\%) do not follow this guideline. Participants 104(68.0\%) checked that if the baby start to cry, stop ventilation and observe respiration for 15 minutes. Then started routine care of new born baby. While 49(32.0\%) do not follow this.

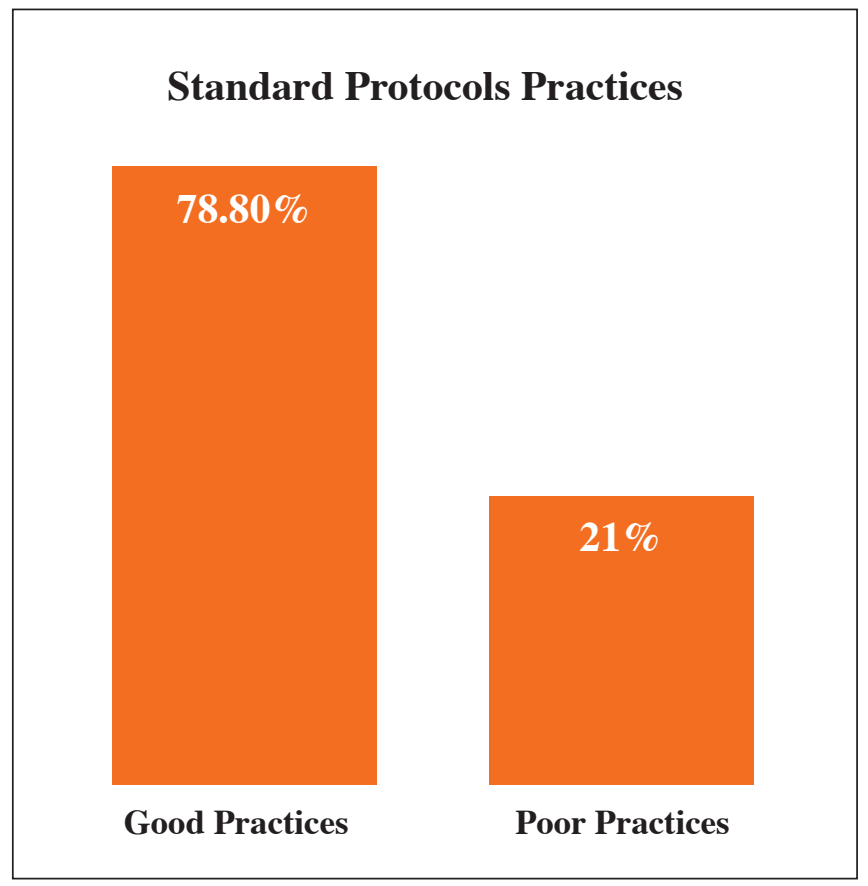

Fig. (1). Standard Protocol Practices among Nurses.

Study concluded that $78.80 \%$ nurses have shown good practices adhering to the standard protocols for the management of birth asphyxia. While $21.2 \%$ nurses perform poor practices (Fig. 1). 
Table 2. Proportions of Nurses that Adhered to Standard Protocols of Resuscitations during Management of Newborn with Birth Asphyxia.

\begin{tabular}{|c|l|c|}
\hline Steps & Standard Protocols & Adherence \% \\
\hline 1 & Wipe the mouth and nose of the neonate with sterile gauze. & $(94.8 \%)$ \\
\hline 2 & Dry the baby of excessive moisture. & $(86.3 \%)$ \\
\hline 3 & Remove wet cloth and wrap baby in warm dry cloth. & $(86.9 \%)$ \\
\hline 4 & Provide warmth and put baby under radiant heater. & $(88.9 \%)$ \\
\hline 5 & $\begin{array}{l}\text { Place the baby on flat surface and position the head of the baby so that the neck is slightly } \\
\text { extended to open the airway. }\end{array}$ & $(90.2 \%)$ \\
\hline 6 & Quickly clear airway. & $(90.8 \%)$ \\
\hline 7 & Reassess the baby after suctioning in order of importance; respirations, heart rate and color. & $(86.3 \%)$ \\
\hline 8 & $\begin{array}{l}\text { If the baby is not breathing, apneic or has gasping respirations or heart rate of less than 100 b/min, } \\
\text { start ventilating with bag and mask. }\end{array}$ & $(84.3 \%)$ \\
\hline 9 & Recheck the newborns neck if it is slightly extended. & $(55.6 \%)$ \\
\hline 10 & $\begin{array}{l}\text { Select appropriate mask size to cover the chin, mouth and nose and check that the mask is properly } \\
\text { sealed over the newborn's nose and mouth. }\end{array}$ & $(81.0 \%)$ \\
\hline 11 & $\begin{array}{l}\text { Once the seal is assured and chest movement is present ventilate the newborn and maintain correct } \\
\text { rate (40 breaths per minute). }\end{array}$ & $(75.5 \%)$ \\
\hline 12 & If chest is not rising, repeat suctioning of the mouth, nose and remove mucus or blood from the airway. & $(68.0 \%)$ \\
\hline 13 & After 30 seconds of proper ventilation, re-evaluate breathing, heart rate and color. & $(79.7 \%)$ \\
\hline 14 & After ventilating for 1 minute, stop and quickly assess if newborn is having spontaneous breathing. & $(66.7 \%)$ \\
\hline 15 & $\begin{array}{l}\text { If the newborn is not breathing or breathing is slow (<30 breaths per minute) or weak or severe in } \\
\text { drawing continue ventilating until spontaneous breathing begins. }\end{array}$ & $(65.4 \%)$ \\
\hline 16 & If newborn starts crying, stop ventilating and continue observing breathing for 15 minutes. & $(68.0 \%)$ \\
\hline 17 & If there is severe in drawing of the chest, ventilate with oxygen if available. & $(81.0 \%)$ \\
\hline 18 & $\begin{array}{l}\text { If the newborn is not breathing regularly after } 20 \text { minutes of ventilation incubate and transfer the baby } \\
\text { for appropriate care for sick new born. }\end{array}$ & $\begin{array}{l}(72.5 \%) \\
\text { If breathing is normal (30 - 60 breaths per minute) and there is no in-drawing or granting and no } \\
\text { further resuscitation is needed, proceed with care of the new born. }\end{array}$ \\
\hline
\end{tabular}

\section{DISCUSSION}

\section{How Nurses Can Identify the Risk of Birth Asphyxia?}

Birth asphyxia, According to WHO (2016) is defined as failure to establish spontaneous respiration at birth. Rwandan neonatology (2012) cited that birth asphyxia is a condition of Hypoxic Ischemic Encephalopathy (HIE), based not only on poor gas exchange but also on low APGAR score [19]. In 1952, Dr. Virginia established APGAR (Appearance, Pulse, Grimace, Activity and Respiration) score to assess the newborn resuscitation needs. The score of 1 minute indicates the neonate has well tolerated the birthing process. 5 minute score shows newborn has tolerated to extra-uterine life. While 7 minute score identify Birth asphyxia case [3].

Nurses Ability to Follow the Standard Protocols of Newborn Resuscitation (Table 2)

In current study nurses and midwifes show good practices as clean the mouth and of the neonate with gauze 145(94.8\%). While another study conducted in south Wollo governmental hospitals, northeast Ethiopia reported almost similar results 133(93\%) nurses dry the new born [20]. In another study conducted in Lucknow city show different results as The majority of the newborns (79.7\%) were washed and dried with sterile cloth soon after delivery [21]. Another cross-sectional observational study done in west Bengal India to assess practice of nurses as drying the newborn and removes wet towel $90(77.6 \%)$ and Wraps with warm towel $76(65.5 \%)$ [18].

Some nurses 104(68.0\%) show average practices in this study towards the step, if chest is not moving, repeat suctioning from mouth, nose to remove mucus or blood and clean the airway. Secretions of amniotic fluid or meconium can obstruct the air way. Similar study conducted in Kenya reported that presence of meconium is the indication of birth asphyxia. It is observed that health workers poorly follow the standard protocols which results in delayed breathing and eventually early death of newborn [22]. Similar results 71 (61.2) was reported by nurses working in west Bengal India, If meconium present, baby not crying, carries out suction first [23].

In this study nurses and midwifes show good practices towards assessment of respirations, heart rate and color 132(86.3\%). While another study done in South Wollo Governmental Hospital, Northeast Ethiopia reported almost 
similar results that nurses assess the new born for color 131(91.6) indicates good practices [24].

In this study majority nurses presents good results 129 $(84.3 \%)$ towards the step that If the baby is not breathing, apnea, gasping and heart rate less than $100 \mathrm{~b} / \mathrm{min}$, start ventilation with bag and mask. According to WHO guidelines best assessment is the breathing. The babies need resuscitation with bag and mask who do not breathe, cry or gasp after 30 seconds after birth. The symptoms as absent breathing, inactivity, pallor, irregular respiration, no cry at birth and cord pulsation may indicate death of newborn due to hypoxia. In that case suction is required so that baby's heart rate falls below 60 beats per minute, undergo ventilation [25]. A study done in North East, Ethiopia said that majority of nurses 142 (99.3) Ventilate the new born from 40 to 60 beats per minute to save the life of newborn [4].

According to current study mostly nurses $124(81.0 \%$ ) adhere this protocol strongly choose suitable size of mask to cover the chin, mouth and nose and make sure that the mask is sealed over the nose and mouth. Mostly nurses $114(75.5 \%)$ follow that protocol Once the seal is checked and chest is moving, start ventilation and keep correct rate (40 breaths per minute). While according to the study in American Academy of Pediatrics revealed their results as 120 (83.9\%)inadequate seal is the reason for failure of bag mask and ventilation [4]. Another cross-sectional observational study done in west Bengal India, to assess the knowledge and practice of nurses towards neonatal resuscitation. mostly Nurses 100 (86.2) was adhere that Check bag and mask during resuscitation of newborn, either appropriately sealed or not [23].

\section{CONCLUSION}

Early detection of Birth asphyxia and management is critical to reduce neonatal mortality in Lahore, Pakistan. Current study revealed that, Nurses have shown good practices $78.8 \%$ adhering to the standard protocols for the management of birth asphyxia. While remaining $21.2 \%$ neglected protocols due to lack of staff nurses, bad attitude, lack of equipments and overburdened. There is in dire need to focus on training of nurses for correct use of Apgar score and monitoring the pregnant women during labor in complete supervision. Appoint experienced and qualified nurses for newborn care. Ensure the availability of necessary equipments for resuscitation and resources to provide excellent care to newborn, so that neonatal mortality should be decreased.

\section{LIMITATIONS}

Firstly, there exist multiple standard practices, but nurses and midwives only follow some steps. Secondly, some other variables like supervisor support, favorable environment and job insecurity may also influence the quality of care for newborn. Thirdly, data is collected only from nurses and midwives of tertiary care hospitals through survey. Which can limit the generalizability of findings in private settings. Future studies should collect data from both private and public hospitals to enrich the findings with close observation.

\section{FINANCIAL SUPPORT}

No financial support received from any institution.

\section{CONFLICT OF INTEREST}

Declared none.

\section{ACKNOWLEDGEMENTS}

Declared none.

\section{REFERENCES}

[1] Kamath-Rayne BD, Berkelhamer SK, Ashish K, Ersdal HL, Niermeyer S. Neonatal resuscitation in global health settings: An examination of the past to prepare for the future. Pediatr Res 2017; 82(2): 194-200. DOI: 10.1038/pr.2017.48

[2] Shikuku DN, Milimo B, Ayebare E, Gisore P, Nalwadda GJ. Quality of care during neonatal resuscitation in kakamega county general hospital, Kenya: A direct observation study. Biomed Res Int 2017; 2017: 2152487.

DOI: $10.1155 / 2017 / 2152487$

[3] Moriyama M, Chayama K, Liu Y, Ya C, Muzembo BA, Rahman MM. Efficacy of a self-management program in patients with chronic viral hepatitis in China. BMC Nurs 2019; 18(1): 44. DOI: $10.1186 / \mathrm{s} 12912-019-0366-7$

[4] Wall SN, Lee AC, Niermeyer S, et al. Neonatal resuscitation in low-resource settings: What, who, and how to overcome challenges to scale up? Int J Gynecol Obstet 2016; 107(Supplement): S47-S64. DOI: 10.1016/j.ijgo.2009.07.013

[5] Bang A, Bellad R, Gisore P, et al. Implementation and evaluation of the helping babies breathe curriculum in three resource limited settings: Does Helping Babies Breathe save lives? A study protocol. BMC Pregnancy Childbirth 2014; 14(1): 116. DOI: $10.1186 / 1471-2393-14-116$

[6] Mehar MF, Khan MA, Saleem R, et al. Risk factors of perinatal asphyxia at Nishtar Hospital Multan. Prof Med J 2020; 27(03): 487-92. DOI: 10.29309/TPMJ/2020.27.03.3176

[7] Mehboob R, Kabir M, Ahmed N, Ahmad FJ. Towards better understanding of the pathogenesis of neuronal respiratory network in sudden perinatal death. Front Neurol 2017; 8: 320. DOI: $10.3389 /$ fneur.2017.00320

[8] Uwingabire F. The prevalence of birth asphyxia, associated factors and outcomes at a district Hospital in Kigali, Rwanda. Rwanda: University of Rwanda 2017; Available at: h t t p s : / / p d f s. s e m a n t i c s c ho 1 ar.org/100f/604ed6de7fb40bf4e3fef8098f74598db881.pdf

[9] WHO. Every newborn: An action plan to end preventable deaths. 2016; Available at: https://www.who.int/mater- 
nal_child_adolescent/newborns/every-newborn/en/

[10] Das MK, Chaudhary C, Bisht SS, et al. Retention of knowledge and skill of birth attendants in newborn care and resuscitation after 1 Year in clinical practice: An experience from India. J Clin Neonatol 2018; 7(2): 89.

DOI: $10.4103 /$ jcn.JCN_9_18

[11] Lee C-T, Hung Y-C, Hu W-L. Complementary therapy with traditional chinese medicine for neonatal hypoxic ischemic encephalopathy. Ischemic Stroke Brain 2018; 89. Available at: https://ww w intechopen.com/books/ische m i c - s t r o k e - o f - b r a i n / c o m plementary-therapy-with-traditional-chinese-medicine-for-ne onatal-hypoxic-ischemic-encephalopathy DOI: 10.5772/intechopen.76373

[12] Wei L, Ren Q, Zhang Y, Wang J. Effects of hyperbaric oxygen and nerve growth factor on the long-term neural behavior of neonatal rats with hypoxic ischemic brain damage. Acta Cir Bras 2017; 32(4): 270-9. DOI: $10.1590 / \mathrm{s} 0102-865020170040000002$

[13] Anokye R, Acheampong E, Anokye J, et al. Use and completion of partograph during labour is associated with a reduced incidence of birth asphyxia: A retrospective study at a peri-urban setting in Ghana. J Health Popul Nutr 2019; 38(1): 12. DOI: 10.1186/s41043-019-0171-7

[14] Kumari RJ. Assessment of Knowledge and Skills of Nursing Personnel Working in NICU and Delivery Room of Selected Tertiary Care Hospital of Lucknow, Uttar Pradesh. J Nurs Sci Pract 2019; 6(2): 21-7.

[15] Ibrahim N, Muhye A, Abdulie S. Prevalence of birth asphyxia and associated factors among neonates delivered in Dilchora Referral Hospital. Clin Mother Child Health 2017; 14(279): 2. DOI: $10.4172 / 2090-7214.1000279$

[16] Gebreegziabher E, Aregawi A, Getinet HJW. Knowledge and skills of neonatal resuscitation of health professionals at a university teaching hospital of Northwest Ethiopia. World J Emerg Med 2014; 5(3): 196-202.

DOI: $10.5847 /$ wjem.j.issn.1920-8642.2014.03.007

[17] Gueye M, Boiro D, Faye P, et al. Évaluation des connaissances et procédures de la réanimation néonatale selon le programme «Helping Babies Breathe»(HBB) par le personnel soignant qualifié au niveau des hôpitaux de référence à Dakar. Kundoc 2017; 30(5-6): 219-24.

DOI: $10.1016 /$ j.jpp.2017.09.001

[18] Anokye R, Acheampong E, Anokye J, et al. Use and completion of partograph during labour is associated with a reduced incidence of birth asphyxia: A retrospective study at a peri-urban setting in Ghana. J Health Popul Nutr 2019; 38(1): 12. DOI: $10.1186 / \mathrm{s} 41043-019-0171-7$

[19] Nyamao NJ. Correlation of maternal characteristics and birth asphyxia at Kenyatta national hospital and Pumwani maternity hospital in Kenya. Dissertation. The university of Nairobi 2017; Available at: https://pdfs.semanticscholar.org/5b30/743f5c2c0eb115c9a19871b21c7a1c2425a5.pdf

[20] Biset G. Knowledge, practice and associated factors toward neonatal resuscitation among nurses and midwifes in south Wollo governmental hospitals. Northeeast Ethiopia 2018. Thesis. Addis Ababa University 2018; Available at: http://etd.aau.edu.et/bitstream/handle/123456789/13804/Gebeyaw $\% 20$ Biset.pdf?sequence $=1 \&$ isAllowed $=\mathrm{y}$

[21] Gupta P, Srivastava V, Kumar V, J, et al. Newborn care practices in urban slums of Lucknow city, UP. Indian J Community Med 2010; 35(1): 82-5.

DOI: $10.4103 / 0970-0218.62570$

[22] Sepeku A, Kohi T. Treatment outcomes of neonatal asphyxia at a national hospital in Dar es Salaam, Tanzania. Afr J Nurs Midwif 2011; 13(2): 43-56.

[23] Basu M. A study on knowledge and practice of neonatal resuscitation among nursing staff. Sri Lanka J Child Health 2014; 43(1): 38-40. DOI: 10.4038/sljch.v43i1.6660

[24] Ezenduka P, Ndie E, Oburoh E. Assessment of knowledge, attitude, and practice of nursing management of birth asphyxia in federal medical centre Asaba, Delta State-Nigeria. Clin Nurs Stud 2016; 4(2): 21-7. DOI: 10.5430/cns.v4n2p21

[25] Shikuku DN, Milimo B, Ayebare E, Gisore P, Nalwadda G. Practice and outcomes of neonatal resuscitation for newborns with birth asphyxia at Kakamega County General Hospital, Kenya: A direct observation study. BMC Pediatr 2018; 18(1): 167. DOI: $10.1186 / \mathrm{s} 12887-018-1127-6$ 